\title{
Environmental and Geo-Referenced Information Modeling for Sustainable Development in Iran
}

\author{
Alireza Gharagozlou ${ }^{1}$, Mahsa Adl $^{2}$ \\ ${ }^{1}$ Geomatics College of National Cartographic Center of Iran, Tehran, Iran \\ ${ }^{2}$ Department of Environment and Energy, Science and Research Branch, Islamic Azad University, Tehran, Iran \\ Email: agharagozlu@yahoo.com
}

Received August 22, 2011; revised October 15, 2011; accepted November 6, 2011

\begin{abstract}
By providing Geo-referenced information, which serves as an important tool for decision-making in land use planning, national mapping agencies can help provide effective monitoring of environmental resources while in many parts of the world lack adequate information in clear. Their role in sustainability and development planning is thus unique and essential. National cartographic centers and national mapping agencies offers example of such national mapping agencies. Accurate information on land and environmental resources is essential to effective land use planning. Key sources of information include topographic maps, aerial photos, satellite images, and data derived from geographic information systems (GIS). At the national level, this information can be used to identify environmental resources, reveal the development potential of the country, and help promote effective ecological studies and sound land use planning with a land use planning approach. This article begins with some general comments on the importance of land use planning, and outlines some current environmental issues and also highlights the connection between roles of Geo-referenced information in land use planning with a sustainable development approach. The discussion describes several key methods of resource identification, with particular emphasis on aerial photography and the existing potentials of Iran in this field. The article also discusses the role that the Geo-referenced information and environmental planning play in developing and promoting geographic information system use to sustainable development and finally present proper models to use environmental information and geo-referenced data for sustainable development.
\end{abstract}

Keywords: GIS; RS; Land Use Planning; Geo-Referenced Information; Sustainable Development; Environment

\section{Introduction}

At the beginning of the $21^{\text {st }}$ century, excessive land use and increased human impacts have imposed significant pressures on the environment worldwide. These effects are increasingly noticeable from a scientific and technical viewpoint, especially in Asian and African countries. Misuse of the land and inadequate growth management impose long-term impacts because of the long duration of excessive land uses, and the long time-frames that are needed to reclaim land that has been poorly used. As a result of past practices, the world now faces decreased natural resources at a time when populations are increasing and pollution problems are growing. In an era when human economic activity affects all areas of the environment, there is no doubt that governments and organizations should plan their land use wisely. Future development should proceed on the basis of proper land use planning, with minimum destruction of the environment. Planning assessments must therefore consider environmental issues, and use environmental information to refine decisions. Gathering information reveals the available poten- tial of the environment; development planning at the nationwide level can help decision-makers identify resources and target their future scientific studies [1].

Geo-referenced information can be seen as forming the "infrastructure" for land use planning. Such information provides a crucial basis for appropriate decision-making by government agencies and other organizations.

\section{Geo-Referenced Information, Land Use Planning and Sustainability}

Numerous species of plants and animals were severely affected, and some of them vanished. Since the late 1970s, statistics show that the number of cities with populations of more than eight million have increased from two to 28 . In addition, water consumption has been increased from 1300 billion to 4200 billion cubic meters annually, gas production has increased from five billion to 25 billion tons per year, and rain forests have decreased by 30 percent. Metal resources also are being used up rapidly: It has been estimated that nickel will be depleted within approximately 55 years, copper within 36 years, zinc within 
25 years, and lead within 21 years. Moreover, each minute, 5.6 hectares of forest are being destroyed. Land is a limited and vulnerable resource. Inattentive and careless land use, together with improper management and unwise decision-making, can compound environmental problems.

By contrast, if land resources are being utilized wisely without being depleted, they can be used perpetually, and this use will be renewable. In order to achieve the goal of sustainable development, more attention must be paid to the past, present, and future uses of land. Today, all nations recognize that they must preserve the natural environment and utilize land's potential in a reasonable manner. However, in many cases, their development projects are still launched with little attention to long-term sustainability, and without having adequate information on the land's capacity to accommodate development. Land development involves a wide range of issues, and thus gives rise to many different viewpoints on land use planning [2]. In Figure 1 in next page classification of major's viewpoints on the role of land use planning in development plans is presented.

\section{Identification of Land Resources and Available Potential}

Land use planning is an iterative or "evolutionary" process, with each step in the process being a prerequisite to the next. From an environmental planning point of view, resource identification is the first step in national resource assessment and overall land use planning. In Figure 2 and Figure 3, Processes of Plan Compilation with and without a Land Use Planning Approach are presen- ted and in Figure 4 we can attention to the environmental impact assessment process that all procedures are important in national level. Different countries use different planning methods. But there is no doubt that comprehensive scientific planning (based on the land's environmental potential), and alignment with the overall social and economic requirements of the individual country, are crucial to appropriate resource use.

In general, natural or ecological resources can be categorized as "physical" and "biological." Physical resources include the land itself, the climate, geological and land formations, and soil. Biological resources include plants and animals. From a sustainability point of view, ecological resources can also be categorized as "fixed" or "unfixed." [3] Fixed resources are those that are permanent in their matrix (such as geology, soil type, land form, and indigenous plant species). Changes in such resources generally are slow, unless they are subject to strong influences from natural or human forces. Unfixed resources are those that are not permanent, and that can change quickly.

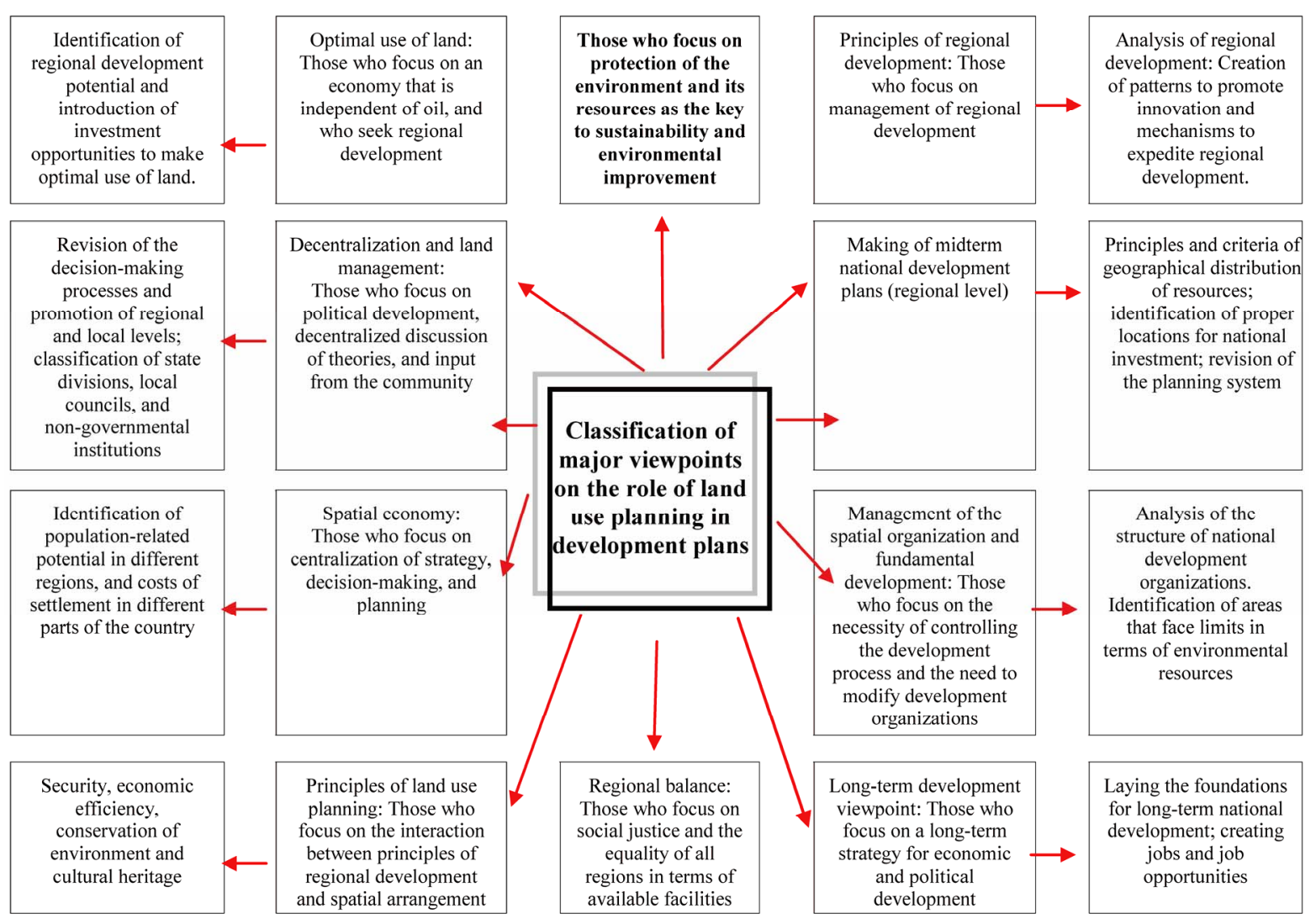

Figure 1. Classification of major viewpoints on the role of land use planning in development plans. 


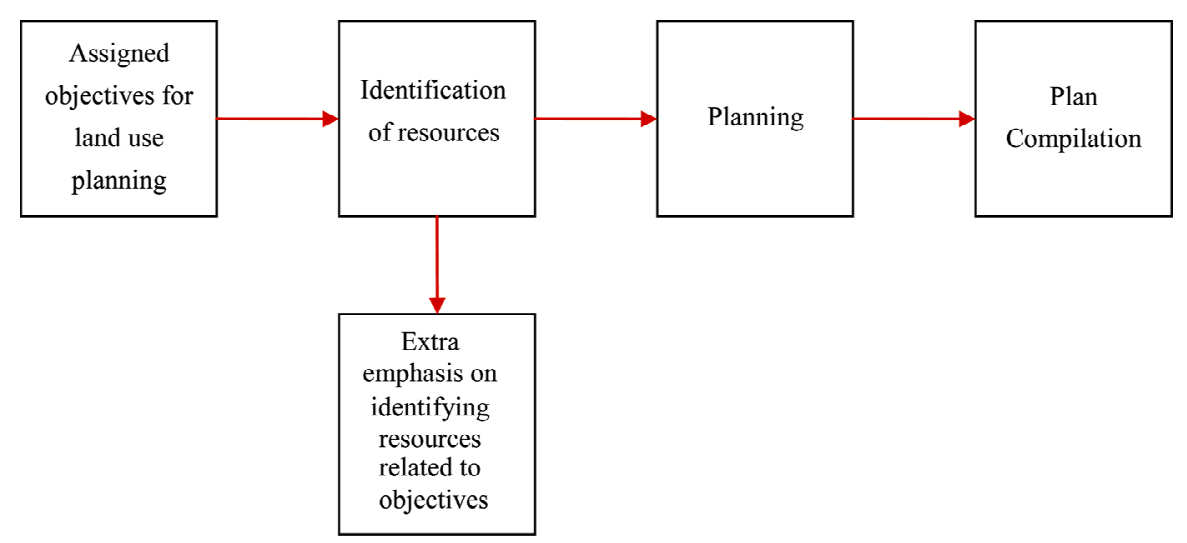

Figure 2. Process of plan compilation without a land use planning approach.

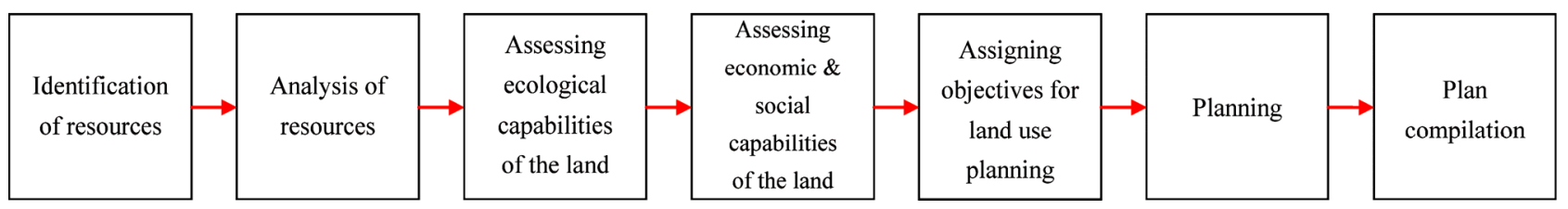

Figure 3. Process of plan compilation with a land use planning approach.

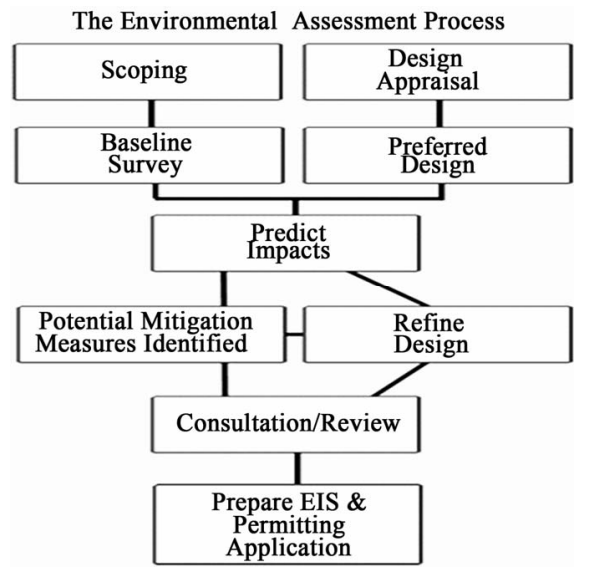

Figure 4. The Environmental Impact Assessment (EIA) process.

\section{Methods of Resource Identification}

A number of methods can be used to identify potential land resources. Key methods include:

- Statistics and sampling

- Aerial photos, satellite images, and topographic maps

- Automatic interpretation of aerial photos and satellite images

- Use of data derived from geographic information systems (GIS)

Exact study methods can be used, and results can be obtained, depending on the subject matter and aims of the particular project.

In Iran several methods are available to identify and understand environmental characteristics such as climate by using statistics, sampling, and direct analysis.
In line with recent technological developments, remote sensing and analysis of satellite data are also widely used for this purpose throughout the world. To identify geomorphology, researchers can interpret satellite images and aerial photos, and can carry out field work. These methods can also help identify the probability of soil erosion.

\subsection{Using and Interpreting Aerial Photography and Resource Assessment}

Environmental assessment requires accurate quantitative data on land characteristics. In the case of inaccessible areas, aerial photography has a role of great importance in preparing the needed data. For comprehensive studies, and for planning undertaken on a country-wide basis, aerial photography methods are recommended as a way of collecting accurate and appropriate information, especially when the areas have not been adequately studied in the past. Aerial photography can save time and expense, and the photographs taken can generally be merged with data gathered from field operations. Using aerial photos is appropriate in many cases, especially when researchers need three-dimensional views, accurate measurements, and the coverage of many different land regions (especially areas that are difficult to reach, such as those at high elevations) [4]. At present, the National Cartographic Center (NCC) in Tehran is responsible for preparing aerial photos and base maps for all parts of the country. NCC is equipped with a very capable aerial photography fleet. The aerial photography department of NCC includes offices for flight and photography, along with specialized functions such as aerial triangulation, photogrammetric computation, graphical editing, three-dimensio- 
nal control of graphical files, and digital image processing.

The NCC photography office has operated continuously for more than 40 years. The NCC fleet performs a diverse range of aerial photography missions throughout the country. The office provides base photos for all areas of the country at the proper scales. The photography office can take vertical and oblique color and black/white photos of the important locations in the country including religious, historical, and cultural sites, and industrial sites and their surrounding areas. Through its photos, the office can capture the land situation in different time periods, showing projects in "before and after" mode, and reveal changes in economic centers and urban areas. Aerial photos and satellite images must be interpreted, either by computer or by a human viewer. Information derived from such photos, along with other data, can then be combined on maps and stored in digitized format or in databases. When aerial photos or satellite images for an entire country the size of Iran are interpreted and combined with other geographical data, it makes available a vast array of information that can be arranged and classified according to geographic location and resource potential.

With such a volume of information, it even becomes possible to perform resource assessments based on maps and their associated data. Users can also directly store information on the environmental potential of each region of the country according to its geographical location. This information can be placed in databases in the form of maps and tables for planners and decision makers.

\subsection{Remote Sensing, GIS and Sustainable Development}

Aerial photography is one of the most commonly used forms of "remote sensing" (RS) [5], a term that refers to collecting data through devices that are situated some distance away from the location being studied. Remote sensing can be conducted by aircraft, satellite, or other means [6].

Data derived from remote sensing are increasingly being used with GIS technology which is a computer-based tool that allows users to integrate and manage geographic data. Geographic information systems can be used in a wide array of different applications. GIS technology is particularly valuable to land use planners because it allows them to search and analyze data quickly.

After finishing the task of resource identification for the purpose of land use planning, ecological data on the land can be converted into maps. Different maps can be created for specific resources and environmental aspects, such as water, climate, land form, geology, and species of plants and animals. Essentially, the most important and probably the most difficult tasks in assessing environmental potential for land use planning purposes are data gathering [7] and analysis.
These steps necessarily involve making detailed maps that illustrate the distribution of resources within particular regions or catchment areas, based on an array of national resource parameters that can be ranged from simple to very complex. These steps necessarily involve making detailed maps that illustrate the distribution of resources within particular regions or catchment areas, based on an array of national resource parameters that can be ranged from simple to very complex.

In Iran, the National Cartographic Center has undertaken the task of organizing and establishing a national geographic database in order to fully utilize the potential of its geographic information system. From the point of view of development and land use planning, especially at the nationwide level, the national geographic information system is a crucial database for planners and decision makers. The NCC's geographic information systems department represents a very important resource for promoting sustainable development in Iran. It offers experience and expertise in essential areas, as well as providing computer capability. Among the main tasks of NCC's GIS department is the establishment of a national topographic database (NTDB). National Cartographic Center plans and coordinates activities in the GIS field in different provinces of Iran. It has established National Geographic Information System (NGIS) councils of GIS users at both the national and the provincial Figure 5 present components of environmental planning by using GIS/RS and in Figure 6 Role of GIS and RS in Land Use Planning with a Sustainable Development Approach is presented.

\section{Conclusions}

The application of Geo-referenced information and their capabilities in land use planning for sustainable development represents a key trend in all countries. Land use planning plays an important role in development throughout the country. When such planning is able to utilize the Geo-referenced information described here, it can offer a comprehensive approach to managing development programs in a manner that promotes long-term sustainability. GIS plays an important role in decision making for sustainable development, given its ability to provide useful information for analysis and assessment.

In land use planning with a sustainable development approach making GIS as a common language for spatial data involves not only a commitment of decision makers to the technology but also requires that the technology commit to the environmental process where decisions are made. Presenting proper models in the filed of roles of Geo-referenced information and environmental planning play in developing and promoting geographic information system use to sustainable development in this paper is a new experience. 


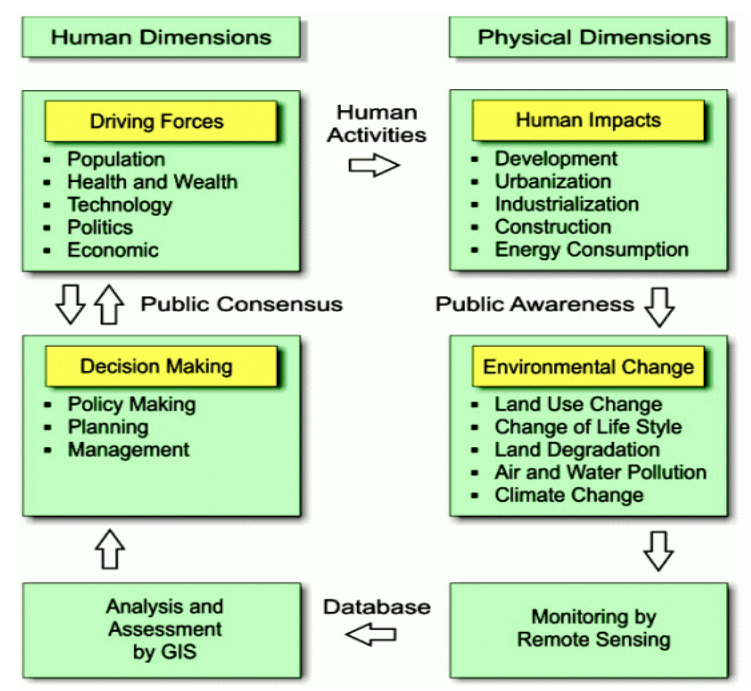

Figure 5. Components of an environmental planning and monitoring and analysis by using GIS and remote sensing.

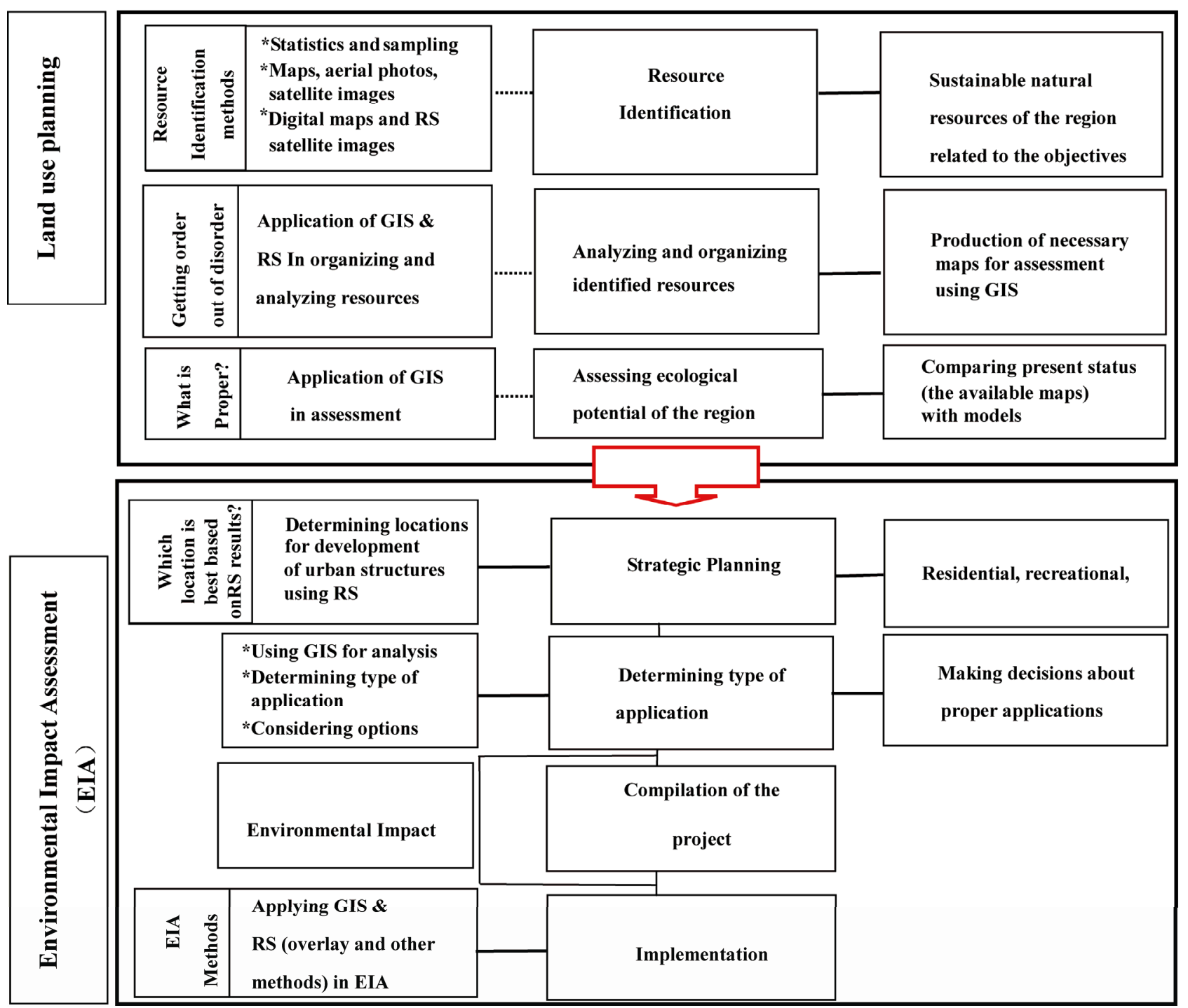

Figure 6. Role of GIS and RS in land use planning with a sustainable development approach. 


\section{REFERENCES}

[1] S. Aronoff, "Geographic Information Systems," GIS Department, National Cartographic Center of Iran, 1994, pp. 45-78.

[2] M. J. Kevany and N. Meyer, "Opportunities and Challenges: A Community Approach to Open Systems,” Community Forum at URISA Spotlights the Open Systems Issues, 1995.

[3] M. Makhdoom, "Fundamental of Land Use Planning," Tehran University, Tehran, 1992, pp. 16-78.

[4] A. H. Benny, "Automatic Relocation of Ground Control Points in Landsat Images," International Journal of Re- mote Sensing, Vol. 4, No. 2, 1983, pp. 335-342. doi:10.1080/01431168308948551

[5] R. Tateishi and D. Hasting, "Global Environmental Databases,” International Society for Photogrammetry and Remote Sensing, Working Group IV/6, 2000.

[6] L. Eklundh and L. Harrie, "Investigation Relationships between Landsat ETM + Sensor Data and Leaf Area Index in a Boreal Conifer Forest," Remote Sensing of Environment, Vol. 78, 2001, pp. 239-251. doi:10.1016/S0034-4257(01)00222-X

[7] S. Beer, "Environmental Planning for Site Development," An Imprint of Chapman and Hall, London, 1990, pp. 102-134. 